\title{
Correlation Between Indicators of the Electronic Testing And the Current Test for Raw Silk
}

\author{
Niu Jiantao1, a , Hu Qi²,b , Xu jianmei ${ }^{3, c}$ \\ ${ }^{1}$ Suzhou Institute of Trade \& Commerce, Suzhou, Jiangsu, China \\ 2 Suzhou University of Science and Technology, Suzhou, Jiangsu, China \\ ${ }^{3}$ Soochow University, Suzhou, Jiangsu, China \\ atjpunjt@126.com, b375689252@qq.com, c xujianmei2002@sina.com
}

\begin{abstract}
Keywords: Raw Silk, Electronic Testing, Seriplane Test, Correlation Coefficient.
Abstract. Five batches of raw silk were tested in the electronic testing for raw silk on the raw silk electronic detector, meanwhile, the current test of raw silk was done in accordance with GB/T 1797-2008 standard for raw silk, and the correlation between indicators of the electronic testing and the current test of raw silk were analyzed by using DPS data processing software. The results showed that there were stronger correlation between the coefficient of variation of the raw silk size (CVeven and CV5m) and the thick and thin defects as well as the medium rough in the electronic testing for raw silk; the coefficient of variation of the raw silk size and the thick and thin defects in the electronic testing for raw silk has stronger positive correlation with the evenness change 2nd degree numbers but stronger negative correlation with neatness in the seriplane test; the neatness and evenness in the seriplane test are the comprehensive reflection of all kinds of indicators in the electronic testing for raw silk.
\end{abstract}

\section{Introduction}

The raw silk as the excellent textile material is the important primary product forming a connecting link between the preceding and the following in the silk industry of our country, and also it is an important export product in China. At present, the current test of raw silk of China is based on the national standard of GB/T 1797-2008 for raw silk and GB/T 1797-2008 for raw silk testing method, and the main testing indicators includes size deviation, maximum size deviation, evenness change 2 nd degree, cleanness and neatness, and the basic level of the raw silk is determined according to the lowest score of the primary five test indicators[1,2]. The current test method of raw silk still belongs to the traditional test method, and the quality indexes of cleanness, neatness and evenness using seriplane test are easily affected by man-made factors to some extent [3]. With the silk products such as zhang velvet satin getting a requirement for the quality of raw silk being higher and higher, and with the development of the electronic testing technology, the evenness degree and defects can be tested on the raw silk electronic detector, which gradually takes place of the traditional seriplane test method of raw silk [4].

In the standards of the electronic testing for raw silk, the electronic testing indicators mainly includes the two big aspects of the coefficient of variation of the raw silk size and the defects [5]. In terms of the silk evenness and defects, Zhou Benli and others found some research results about the correlation study of the testing by Uster Evenness Tester and the seriplane testing[6-10]. But because some peculiar defects of raw silk such as crack silk and defects can not be accurately tested when using Uster-III type and other types of Uster[4], thereby being some using limitations. In the research process of the electronic testing for raw silk, the test equipment used by us was the raw silk electronic detector developed by the silk test center of Zhejiang Entry-exit Inspection and Quarantine Bureau, and the instrument is different from the testing method of Uster Evenness Tester, and there are also some difference between the classification of all kinds of defects by the two instrument. Based on the data 
obtained from the raw silk electronic detector, the correlation between indicators of the electronic testing and the current test of raw silk was analyzed.

\section{Experiment}

Experiment Materials. In this experiment, five batches of different specifications and grades of raw silk inspected in the silk test center of Zhejiang Entry-exit Inspection and Quarantine Bureau were used, which were respectively from the silk reeling production enterprises in different regions. The electronic testing and current test of raw silk were done at the same time for each batch of raw silk.

Electronic Test for Raw Silk. In the electronic testing for raw silk, the testing indicator primarily includes the two aspects of the coefficient of variation of the raw silk size and the defects.

Coefficient of Variation of the Raw Silk Size. In 1995 the international silk association published the 95 raw silk brief guide, putting forward the proposal that the coefficient of variation of the raw silk size $(\mathrm{CV})$ was taken as the main testing indicator. The $C V$ is defined as follows: for a piece of raw silk, after the continuous detection of the size was done according to a certain testing silk length, the raw silk size time series of $\mathrm{x}_{1}, \mathrm{x}_{2}, \mathrm{x}_{3}, \cdots, \mathrm{x}_{\mathrm{n}}$ with the mean value as $\mu$ and the mean square deviation as $\sigma$ can be obtained, thus $C V$ can be expressed by the following formula.

$$
C V=100 \frac{\sigma}{\mu}(\%) \text {. }
$$

As the quality index of the raw silk test, $C V$ makes the quality of different specifications of raw silk comparable[10]. In this study, $C V$ for the testing silk length as $1 \mathrm{~cm} \quad\left(C V_{\text {even }}\right)$ and $C V$ for the testing silk length as $5 \mathrm{~m}\left(C V_{5 m}\right)$ were primarily investigated.

Defects of Raw Silk. In this research, there were some difference between the classification of the defects of the raw silk in the electronic testing and the classification method of the research of the predecessors [5-10]. Here, the defects of the raw silk in the electronic testing were divided into three types of slubs, thick defects and thin defects.

The slubs in this study refers to the defects that the mass of the tested defects sample has surpassed $80 \%$ of the average mass of the examined sample and the length is more than $1 \mathrm{~mm}$. The slubs can be divided into three categories according to the size: large slub, medium slub and small slub [3]. The thick defects are defined as the ones that the mass of the examined sample size has surpassed $35 \%$ of the average mass of the examined sample and the length is between $10 \mathrm{~mm}$ and $600 \mathrm{~mm}$ or more; The thin defects are defined as the ones that the mass of the examined sample size has been less than $15 \%$ of the average mass of the examined sample and the length is between $10 \mathrm{~mm}$ and $600 \mathrm{~mm}$ or more.

Electronic Testing for Raw Silk. In this experiment, the raw silk electronic detector which is also called raw silk electronic analyzer developed by the silk test center of Zhejiang Entry-exit Inspection and Quarantine Bureau was used. When testing the defects of the raw silk in the electronic testing, 15 to 20 ten thousand meters long of each batch was tested and the measurement speed is $600 \mathrm{~m} / \mathrm{min}$, and on this account the total number of defects was tested, which was then converted into the average number of defects per unit length within $1000 \mathrm{~m}$.

Current Test of Raw Silk. According to the current national standard of GB/T 1797-2008 for raw silk, the main testing indicators of the quality of raw silk includes size deviation, maximum size deviation, evenness change 2nd degree, cleanness and neatness, of which size deviation and maximum size deviation are the raw silk size test, and the evenness, cleanness and neatness adopt the seriplane test.

Size Test. The size indicates the thickness degree of the silk. The size deviation refers to the degree that the size of each skein of raw silk in the whole batches deviates the average size. The maximum size deviation refers to the largest difference between the average value of the thinnest or the thickest size in the whole and the average size taking $2 \%$ of the whole skeins. 
Seriplane Test. The evenness indicates the degree of uniformity. The evenness test is also called the stripe test, and the evenness change can be classified with the evenness change 1st degree, the evenness change 2 nd degree and the evenness 3 rd degree, of which the evenness change 2 nd degree is the main test indicator. The cleanness testing mainly tests the bigger slubs as well as their category and number in the raw silk with a certain long. The neatness testing mainly test the numbers and distributions of all kinds of small defects on the raw silk, and the small defects includes small ring, small bran, crack silk and those small type slubs which does not belong to the neatness scope.

In this experiment, the evaluation of the seriplane test was done by four professional inspectors after respectively testing the five batches of raw silk, and the evaluation method and standard were implemented according to the national standard of GB/T 1797-2008 for raw silk and GB/T 1797-2008 for raw silk testing method.

\section{Result and Analysis}

Result. According to the electronic testing for the five batches of raw silk, the defects of big slub, medium slub, small slub, thick and thin defects per unit length tested were shown in Table 1; the main testing indicators by the raw silk traditional test were shown in detail in Table 2.

Table 1 The Main Electronic Testing Indicators of The Five Batches of Raw Silk

\begin{tabular}{cccccccc}
\hline \multirow{2}{*}{ Batch } & \multicolumn{5}{c}{$C V(\%)$} & \multicolumn{5}{c}{ Average Defects (per 1000 meters) } \\
\cline { 2 - 7 } & $C V_{\text {even }}$ & $C V_{5 m}$ & Big Slub & Medium Slub & Small Sub & Thick Defect & Thin Defect \\
\hline A & 7.216 & 4.529 & 0.028 & 0.028 & 0.233 & 2.006 & 2.422 \\
B & 8.953 & 6.632 & 0.093 & 0.083 & 0.697 & 5.583 & 9.069 \\
C & 6.847 & 4.136 & 0.108 & 0.034 & 0.554 & 1.367 & 2.484 \\
D & 7.542 & 4.777 & 0.130 & 0.031 & 0.552 & 2.078 & 3.906 \\
E & 9.848 & 7.201 & 0.216 & 0.078 & 0.823 & 6.625 & 9.552 \\
\hline
\end{tabular}

By using DPS data processing software, the correlation between indicators of the electronic testing for raw silk were analyzed, and the detailed correlation coefficient was shown in Table 3, meanwhile, the correlation between the $C V$ and defect indicators of the electronic testing for raw silk and the main current test indicators were analyzed, and the detailed correlation coefficient was shown in Table 4.

Table 2 The Main Current Test Indicators of The Five Batches of Raw Silk

\begin{tabular}{|c|c|c|c|c|c|c|c|}
\hline \multirow[b]{2}{*}{ Batch } & \multicolumn{7}{|c|}{ Main Testing Indicators of Raw Silk } \\
\hline & \multicolumn{2}{|c|}{ Size Deviation } & $\begin{array}{l}\text { Maximum Size } \\
\text { Deviation }\end{array}$ & \multicolumn{2}{|c|}{$\begin{array}{l}\text { Evenness Change } \\
\text { 2nd Degree }\end{array}$} & $\begin{array}{c}\text { Cleannes } \\
\mathrm{s}\end{array}$ & $\begin{array}{c}\text { Neatnes } \\
\mathrm{s}\end{array}$ \\
\hline $\bar{A}$ & & 1.37 & 3.19 & 0 & & 99.3 & 95.90 \\
\hline B & & 1.30 & 3.05 & 3 & & 97.6 & 93.70 \\
\hline $\mathrm{C}$ & & 1.17 & 3.00 & 0 & & 98.5 & 95.55 \\
\hline $\mathrm{D}$ & & 0.98 & 2.52 & 0 & & 98.1 & 95.15 \\
\hline $\mathrm{E}$ & & 1.52 & 4.94 & 2 & & 98.8 & 93.45 \\
\hline \multicolumn{2}{|c|}{ Indicator } & Big Slub & Medium Slub & Small Sub & \multicolumn{2}{|c|}{ Thick Defect $\mathrm{T}$} & in Defect \\
\hline \multicolumn{2}{|c|}{$C V_{\text {even }}$} & 0.68 & 0.92 & 0.79 & \multicolumn{2}{|c|}{0.99} & 0.97 \\
\hline \multicolumn{2}{|c|}{$C V_{5 m}$} & 0.62 & 0.95 & 0.78 & \multicolumn{2}{|c|}{0.99} & 0.99 \\
\hline
\end{tabular}

Notes: $\mathrm{r}_{0.1}(3)=0.8054 ; \mathrm{r}_{0.05}(3)=0.8784 ; \mathrm{r}_{0.01}(3)=0.9587$. 
Table 4 Correlation Between $C V$ and Defect Indicators of The Electronic Testing for Raw Silk and the Main Current Test Indicators

\begin{tabular}{ccc|ccc}
\hline \multirow{2}{*}{$\begin{array}{c}\text { Electronic Testing } \\
\text { for Raw Silk }\end{array}$} & $\begin{array}{c}\text { Size } \\
\text { Deviation }\end{array}$ & $\begin{array}{c}\text { Maximum } \\
\text { Size } \\
\text { Deviation }\end{array}$ & $\begin{array}{c}\text { Evenness Change } \\
\text { 2nd Degree }\end{array}$ & Cleanness & Neatness \\
\hline$C V_{\text {even }}$ & 0.64 & 0.76 & 0.86 & -0.22 & -0.96 \\
$C V_{5 m}$ & 0.63 & 0.71 & 0.91 & -0.28 & -0.97 \\
Big Slub & 0.22 & 0.68 & 0.35 & -0.14 & -0.69 \\
Medium Slub & 0.58 & 0.59 & 0.98 & -0.44 & -0.97 \\
Small Slub & 0.22 & 0.54 & 0.70 & -0.52 & -0.89 \\
Thick Defect & 0.67 & 0.73 & 0.91 & -0.25 & -0.97 \\
Thin Defect & 0.54 & 0.63 & 0.94 & -0.41 & -0.99 \\
\hline
\end{tabular}

Notes: $r_{0.1}(3)=0.8054 ; r_{0.05}(3)=0.8784 ; r_{0.01}(3)=0.9587$.

Analysis and Discussion. From Table 3 , it can be seen that $C V$ ( $C V_{\text {even }}$ and $\left.C V_{5 m}\right)$ had stronger correlation with the indicators of thick defect, thin defect and medium slub but common correlation with the big slub and small slub. $C V$ mainly reflects the difference degree of the size of different pieces of raw silk, while the indicators of the thick and thin defects reflects the numbers that the size is thicker or thinner than a certain size on a piece of raw silk. Therefore, $C V$ had stronger correlation with the thick defect and thin defect, which was consistent with the research result of R. Chattopadhyay [9]. In this experiment, itwas found that $C V$ had stronger correlation with the indicators of medium slub but common correlation with the big slub and small slub, we infer that this may be related to the scope of the define of each indicator, which remains to be analyzed and studied for further.

It can be observed from Table 4 that $C V\left(C V_{\text {even }}\right.$ and $\left.C V_{5 m}\right)$ of the electronic testing had stronger positive correlation with evenness change 2 nd degree of the seriplane test and stronger negative correlation with neatness, while it had weaker correlation between size deviation, maximum size deviation and cleanness. Both $C V$ and evenness reflect the unevenness degree change among pieces of raw silk, so there were stronger positive correlations between them.

Because the scores of the cleanness and neatness adopt the scoring criteria of deducting points, the more the defects, the lower the score, therefore the scores of the cleanness and neatness had negative correlation with several related indicators of the electronic testing. Among the three kinds of slubs in the electronic testing, medium slub had stronger correlation with evenness change 2 nd degree and neatness, and small slub also had stronger negative correlation with neatness. The neatness testing mainly test the numbers and distributions of all kinds of small defects on the raw silk, and the small defects includes small ring, small bran, crack silk and those small type slubs which does not belong to the neatness scope. According to the research of Zhou Benli and others [8], the slubs measured by UT instrument had more significant correlation with the neatness score obtained by seriplane test, while it had weaker correlation with long and short defects. In this experiment, three kinds of slubs all had weak negative correlation with the neatness score, which may be influenced by the evaluation standard of two different kinds of testing methods.

It also can be observed from Table 4, the thick and thin defects in the electronic testing for raw silk had very significant positive correlation with the evenness change 2 nd degree numbers and stronger negative correlation with neatness, but it had weaker correlation with size deviation, maximum size deviation and cleanness. R. Chattopadhyay found the thick and thin defects in the electronic testing had stronger correlation with $C V$, evenness change 2nd degree and neatness [9], which was consistent with the research result of this experiment. In combination with the previous analysis, it can be found that both the evenness change 2 nd degree and neatness had tronger correlation with $C V$, medium slub, small slub, 
thick defect and thin defect. In the seriplane test, neatness and evenness evaluate the quality rating by contrasting the sample photos, thus it can be thought that the neatness and evenness in the seriplane test are the comprehensive reflection of all kinds of indicators in the electronic testing for raw silk.

\section{Summary}

Based on the data obtained from the raw silk electronic detector, this paper analyzed the correlation between indicators of the electronic testing and the current test of raw silk, and the main conclusions were that there were stronger correlation between the coefficient of variation of the raw silk size $\left(C V_{\text {even }}\right.$ and $C V_{5 m}$ )and the thick and thin defects as well as the medium rough in the electronic testing for raw silk; the coefficient of variation of the raw silk size and the thick and thin defects in the electronic testing for raw silk has stronger positive correlation with the evenness change 2nd degree numbers but stronger negative correlation with neatness in the seriplane test; among the three kinds of slubs in the electronic testing, medium slub had stronger correlation with evenness change 2 nd degree and neatness, and small slub also had stronger negative correlation with neatness; the neatness and evenness in the seriplane test are the comprehensive reflection of all kinds of indicators in the electronic testing for raw silk.

\section{Acknowledgement}

This work was supported by Suzhou Science and Technology Bureau People's Livelihood Science and Technology Program, China, grant SS201512.

\section{References}

[1] GB/T 1797-2008. Raw Silk, 2008.

[2] GB/T 1798 - 2008. Raw Silk Experimental Methods, 2008.

[3] J.T. NIU, Q. HU, J.M. XU, et al, Discussion on the slubs distribution in the electronic testing of raw silk, J. Silk, 3(2011) 26-28.

[4] Y. Zhou, Research and prospect of electronic detection technology for raw silk, J. Silk, 9 (2009) 42-45.

[5] Information on http://www.esilk.net/web/view.aspx?AID=110400

[6] H. X Xu, The repeatability of the seriplane grading and the Uster tester 1-S, J. Suzhou Institute of Silk Textile Technology, 2 (1987) 19-23.

[7] B.L Zhou, H.X Xu, Correlation between indexes of seriplane grading and uster tester 1-S, J. Suzhou Institute of Silk Textile Technology, 3(1985) 37-53.

[8] B.L Zhou, H.X Xu, on the Correlation between the indexes of seriplane grading and uster tester 1-S, J. Suzhou Institute of Silk Textile Technology, 3(1986) 1-10.

[9] R. Chattopadhyay, S. Das, M.L. Gulrajani, et al, a comparison between the quality attributes of silk yarn using the uster and seriplane test systems, Journal of the Textile Institute, 2 (1997) 92-98.

[10] Z.X Xu, Discussion on the grading method of the size deviation for raw silk, J. Zhejiang Engineering College, 2 (2001) 85-87. 